\title{
Effect of whitening dentifrices containing optical agent on the variation of color, roughness and mass of a nanoparticulate composite resin
}

\author{
Efeito de dentifrícios branqueadores contendo agente óptico na variação da \\ cor, rugosidade e massa de uma resina composta nanoparticulada \\ Rafaela Silva OLIVEIRA ${ }^{a *}$ (D), Hannah Barros SIMÕES ${ }^{b}$ (D) , Natália Nascimento ODILON ${ }^{a}$ (i), \\ Max José Pimenta LIMA ${ }^{a}$ (1) , Elisângela de Jesus CAMPOS ${ }^{a}$ (i) \\ aUFBA - Universidade Federal da Bahia, Instituto de Ciências da Saúde, Salvador, BA, Brasil \\ bUFBA - Universidade Federal da Bahia, Faculdade de Odontologia, Salvador, BA, Brasil
}

\begin{abstract}
How to cite: Oliveira RS, Simões HB, Odilon NN, Lima MJP, Campos EJ. Effect of whitening dentifrices containing optical agent on the variation of color, roughness and mass of a nanoparticulate composite resin. Rev Odontol UNESP. 2020;49:e20200073 https://doi.org/10.1590/1807-2577.07320
\end{abstract}

\begin{abstract}
Resumo
Introdução: 0 Blue covarine é um pigmento que promove alterações ópticas nas superfícies dentárias proporcionando o seu branqueamento. Objetivo: Avaliar in vitro o efeito de dentifrícios branqueadores contendo Blue covarine em resina composta nanoparticulada submetida a escurecimento artificial. Material e método: 160 corpos de prova (CPs) de resina composta nanoparticulada FILTEK Z350XT foram divididos aleatoriamente em dois experimentos: Experimento I- 8 grupos $(n=10)$ submetidos a escovação com escova elétrica por 1 mês; Experimento II- 8 grupos (n=10) submetidos a escovação simulada por 6, 12 e 24 meses. Os grupos foram distribuídos de acordo com a solução/dentifrício testado: GC (água destilada) e 7 grupos teste (GT1-Coltene Herjos, GT2- Colgate Total 12 Clean Mint, GT3- Colgate Luminous White Brilliant Mint, GT4- Oral B 3D White Perfection, GT5- Close Up White Now Glacier Fresh, GT6- Close Up White Attraction Diamond e GT7- Sorriso Xtreme White Evolution). Resultado: No experimento I, houve maior $\Delta$ E no GT6 com relação ao GC, GT2, GT4 e GT5, que não diferiram entre si. No experimento II, após 24 meses de escovação houve maior $\Delta \mathrm{E}$ nos grupos GT6 e GT7. Após 24 meses de escovação simulada não houve alteração da rugosidade nem perda de massa em nenhum grupo. Conclusão: 0 efeito branqueador promovido pelos dentifrícios contendo o agente Blue covarine parece estar relacionado à associação deste agente com os abrasivos presentes nas formulações dos dentifrícios branqueadores.
\end{abstract}

Descritores: Dentifrícios; Blue covarine; agentes branqueadores; resinas compostas.

\begin{abstract}
Introduction: Blue covarine is a pigment that promotes optical changes in dental surfaces, providing whitening. Objective: To evaluate in vitro the effect of bleaching dentifrices containing Blue covarine in nanoparticulate composite resin subjected to artificial darkening. Material and method: One hundred sixty (160) specimens (PBs) of FILTEK Z350XT nanoparticulate composite resin were randomly divided into two experiments: Experiment I - 8 groups ( $\mathrm{n}=10)$ submitted to brushing with an electric toothbrush for 1 month; Experiment II - 8 groups ( $\mathrm{n}=10$ ) submitted to simulated brushing for 6,12 and 24 months. Groups were distributed according to the solution/dentifrice tested: CG (distilled water) and 7 test groups (GT1- Coltene Herjos, GT2-Colgate Total 12 Clean Mint, GT3- Colgate Luminous White Brilliant Mint, GT4- Oral B 3D White Perfection, GT5- Close Up White Now Glacier Fresh, GT6- Close Up White Attraction Diamond and GT7- Sorriso Xtreme White Evolution). Result: In Experiment I, there was greater $\triangle \mathrm{E}$ in GT6 in relation to CG, GT2, GT4 and GT5, with no differences among them. In Experiment II, after 24 months of brushing, there was greater $\Delta \mathrm{E}$ in groups GT6 and GT7. After 24 months of simulated brushing, there was no change in roughness or loss of mass in any group. Conclusion: The whitening effect promoted by dentifrices containing the agent Blue covarine seems to be related to the association of this agent with the abrasives present in the formulations of whitening dentifrices.
\end{abstract}

Descriptors: Dentifrices; Blue covarine; whitening agents; composite resins. 


\section{INTRODUCTION}

In recent years, the search for a pleasant smile has increased the demand for aesthetic procedures in dental clinics. Tooth color is considered one of the most common causes of personal dissatisfaction, and is one of the main factors found in the aesthetics of the smile. In this context, having darkened or stained teeth can cause social embarrassment and a negative self-image in individuals ${ }^{1,2}$.

Tooth color results from the combination of intrinsic and extrinsic stains. Intrinsic tooth coloring is associated with the properties of dispersion and absorption of light in the enamel and in the dentin. Extrinsic tooth coloring is associated with the adsorption of chromogens on the surface of the enamel and acquired film. It can be removed and controlled by the abrasive action of dentifrices ${ }^{3}$.

Darkening of the teeth has become one of the most frequent complaints reported by patients. To contend with this demand, dental whitening may be obtained through in-office bleaching or through the daily use of whitening dentifrices ${ }^{2}$. These dentifrices have a combination of abrasive systems, and those with the capacity to clean the dental surfaces with minimal abrasiveness are considered effective. The ideal dentifrice should promote the cleaning and polishing of the dental surfaces without causing abrasion of the enamel and the restorations ${ }^{4}$.

Whitening dentifrices, in addition to containing agents which provide dental whitening, also have therapeutic agents and are designed for daily use. They represent an easy access, low-cost resource. These dentifrices may contain mechanical, chemical and optical whitening agents, represented, respectively, by abrasives, peroxides and the Blue covarine pigment, associated or $\operatorname{not}^{1,2}$.

Dental whitening, obtained through the use of whitening dentifrices, occurs by removing extrinsic stains and by depositing optical agents, such as Blue covarine, on the dental surface. The action of the dentifrice containing Blue covarine is based on the modification of the perception of the color of the tooth by the deposition of a thin, blue-colored film on the dental surface, giving a temporary whitening effect ${ }^{1,5,6}$.

Due to the increased supply of whitening dentifrices, it is necessary to study their effects on restorative materials, as they may cause alterations in the roughness and mass of these materials and not meet the expectations of the patients regarding the desired whitening. The aim of the present study was to evaluate in vitro the effect of whitening dentifrices containing an optical agent, Blue covarine, on a nanoparticulate composite resin subjected to artificial darkening. The tested hypotheses evaluated whether there are differences among the groups and times regarding the variables of color, roughness and mass. Null Hypothesis (1): There are no differences among the groups regarding the variables of color, roughness and mass. Null Hypothesis (2): There are no differences among the times regarding the variables of color, roughness and mass.

\section{MATERIAL AND METHOD}

This is an in vitro experimental study, conducted in two stages in the Oral Biochemical Laboratory of the Institute of Health Sciences - UFBA. To conduct the present study, 160 specimens (SPs) of nanoparticulate composite resin, FILTEK Z350XT (3M ESPE ${ }^{\circledR}$, Dental Products, St. Paul, Minnesota, USA), color A2B, universal restorative, were randomly divided into two groups according to the type of brushing, electric toothbrush or simulated toothbrushing machine. Experiment I - 8 groups $(n=10)$, subjected to brushing with an electric toothbrush for a period of one month. Experiment II -8 groups $(n=10)$, subjected to simulated brushing with a toothbrushing machine for periods of 6,12 and 24 months. The same dentifrices were used in the two experiments (Table 1). 
Table 1. Division of groups according to the composition of the dentifrice, manufacturer and whitening agents present

\begin{tabular}{|c|c|c|c|c|c|}
\hline & \multirow[b]{2}{*}{ Groups } & \multirow{2}{*}{$\begin{array}{c}\text { Dentifrice/ } \\
\text { Solution }\end{array}$} & \multirow[b]{2}{*}{ Composition/Manufacturer } & \multicolumn{2}{|c|}{ Whitening agents } \\
\hline & & & & $\begin{array}{l}\text { Mechanical } \\
\text { agente }\end{array}$ & $\begin{array}{l}\text { Optical } \\
\text { agent }\end{array}$ \\
\hline 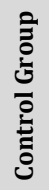 & GC & Distilled water & - & - & - \\
\hline \multirow{11}{*}{ 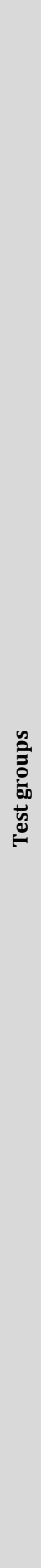 } & GT1 & Coltene Herjos & $\begin{array}{l}\text { Water, sodium lauryl sulfate, calcium carbonate, D-sorbitol, } \\
\text { propylene glycol, sodium fluoride, carboxymethylcellulose, } \\
\text { sodium saccharin, quartz, silica, methylparaben, } \\
\text { formaldehyde, polymethylsiloxane, aroma. } \\
\text { Manufacturer: Coltene. }\end{array}$ & $\begin{array}{l}\text { Calcium } \\
\text { carbonate } \\
\text { Quartz }\end{array}$ & - \\
\hline & GT2 & $\begin{array}{c}\text { Colgate Total } 12 \\
\text { Clean Mint }\end{array}$ & $\begin{array}{l}\text { Sodium fluoride } 0.32 \% \text { ( } 1450 \mathrm{ppm} \text { fluorine), water, sorbitol, } \\
\text { hydrated silica, sodium lauryl sulfate, PVM/MA copolymer, } \\
\text { flavor, carrageenan, sodium hydroxide, sodium saccharin, } \\
\text { titanium dioxide and limonene. } \\
\text { Manufacturer: Colgate-Palmolive. }\end{array}$ & Hydrated silica & - \\
\hline & GT3 & $\begin{array}{c}\text { Colgate } \\
\text { Luminous } \\
\text { White Brilliant } \\
\text { Mint }\end{array}$ & $\begin{array}{l}\text { Water, hydrated silica, sorbitol, glycerin, pentasodium } \\
\text { triphosphate, PEG-12, tetrapotassium pyrophosphate, } \\
\text { sodium lauryl sulphate, aroma, cellulose gum, } \\
\text { polyethylene, cocamidopropyl betaine, xanthan gum, } \\
\text { sodium saccharin, sodium hydroxide (sodium fluoride } \\
\text { (1,100 ppm), CI 77891, blue Lake CI } 42090 \text { blue no. 1, } \\
\text { aluminum lacquer CI } 42090 . \\
\text { Manufacturer: Colgate-Palmolive. }\end{array}$ & Hydrated silica & - \\
\hline & GT4 & $\begin{array}{l}\text { Oral B 3D White } \\
\text { Perfection }\end{array}$ & $\begin{array}{l}\text { Sodium fluoride (1,100 ppm), glycerin, hydrated silica, } \\
\text { sodium hexametaphosphate, water, PEG-6, pentasodium } \\
\text { triphosphate, sodium lauryl sulfate, carrageenan, } \\
\text { cocamidopropyl betaine, mica, CI 77019, sodium } \\
\text { saccharin, PEG-20M, gum xanthan, CI 77891, sucralose, } \\
\text { Limonene, Blue covarine CI 74160. }\end{array}$ & Hydrated silica & $\begin{array}{c}\text { Blue } \\
\text { covarine }\end{array}$ \\
\hline & & & Manufacturer: Procter \& Gamble (P\&G). & Mica & (CI 74160) \\
\hline & GT5 & $\begin{array}{l}\text { Close up White } \\
\text { Now Glacier } \\
\text { Fresh }\end{array}$ & $\begin{array}{l}\text { Sorbitol, water, hydrated silica, sodium lauryl sulfate, PEG- } \\
\text { 32, aroma, cellulose gum, sodium fluoride (1,450 ppm), } \\
\text { pentasodium triphosphate, sodium saccharin, PVM/MA } \\
\text { copolymer, CI 74160, mica, titanium dioxide, limonene. }\end{array}$ & Hydrated silica & $\begin{array}{c}\text { Blue } \\
\text { covarine }\end{array}$ \\
\hline & & & Manufacturer: Unilever. & Mica & (CI 74160) \\
\hline & GT6 & $\begin{array}{l}\text { Close up } \\
\text { Attraction } \\
\text { Diamond }\end{array}$ & $\begin{array}{l}\text { Sorbitol, water, hydrated silica, sodium lauryl sulfate, PEG-32 } \\
\text { aroma, mica cellulose gum, sodium fluoride (1,450 ppm), } \\
\text { sodium saccharin, pentasodium triphosphate, PVM/MA } \\
\text { copolymer, titanium dioxide CI 74160, Limonene. }\end{array}$ & Hydrated silica & $\begin{array}{c}\text { Blue } \\
\text { covarine }\end{array}$ \\
\hline & & & Manufacturer: Unilever. & Mica & (CI 74160) \\
\hline & GT7 & $\begin{array}{l}\text { Sorriso Xtreme } \\
\text { White Evolution }\end{array}$ & $\begin{array}{l}\text { Water, hydrated silica, sorbitol, glycerin, PEG-12, } \\
\text { pentasodium triphosphate, tetrapotassium } \\
\text { pyrophosphate, sodium lauryl sulphate, aroma, } \\
\text { cellulose gum, cocamidopropyl betaine, sodium } \\
\text { fluoride (1,450 ppm), sodium saccharin, xanthan gum, } \\
\text { sodium hydroxide, CI 74160, CI } 42090 .\end{array}$ & Hydrated silica & $\begin{array}{c}\text { Blue } \\
\text { covarine }\end{array}$ \\
\hline & & & Manufacturer: Colgate-Palmolive. & & (CI 74160) \\
\hline
\end{tabular}




\section{Preparation of the Specimens}

To construct the SPs, a bipartite metallic matrix (Odeme $\left.{ }^{\circledR}\right)$ with $5 \mathrm{~mm}$ diameter and $3 \mathrm{~mm}$ thickness was used, into which $2 \mathrm{~mm}$ increments of the composite resin FILTEK Z350 XT were inserted. Photopolymerization was conducted using the Dabi Atlante DB Photopolymerizer (Dabi ${ }^{\circledR}$, intensity $>500 \mathrm{~m} \mathrm{~W} / \mathrm{cm}^{2}$, Ribeirão Preto, Brazil) at a distance of $1 \mathrm{~cm}$ for $40 \mathrm{~s}$ per increment, according to the manufacturer's $\left(3 \mathrm{M}^{\circledR}\right.$, Minnesota, USA) instructions.

\section{Stabilization of the Mass}

After the preparation, the SPs were kept in distilled water at $37^{\circ} \mathrm{C}$ in a Q316M microbiological oven (Quimis ${ }^{\circledR}$ Ltda., Diadema, São Paulo, Brazil), simulating the oral environment in individual containers until the complete stabilization of the mass (g). This was verified by daily weighing.

\section{Embedding Into Orthophthalic Resin}

After stabilization of the mass, the SPs were embedded in Orthophthalic Crystal Resin (Centerglass ${ }^{\circledR}$ ), to fix the SPs, leaving exposed only the surface to be analyzed. After curing, the SPs were removed from the molds and stored in distilled water at $37^{\circ} \mathrm{C}$ in a $\mathrm{Q} 316 \mathrm{M}$ microbiological oven.

\section{Polishing of the Specimens}

Each SP was polished in Politriz (PL V060/Biopdi, São Carlos, SP, Brazil), using non-adhesive, metallographic sandpaper of increasing granularity $(400,600$ and 1200) at low speed, adapted from Silveira et al. 72012.

\section{Darkening of the Specimens}

After polishing, all SPs were kept at $37^{\circ}$ in a instant coffee solution (Nescafé Tradição Forte, Nestlé Brazil, LTDA), prepared according to the manufacturer's instructions, for 14 days with daily exchange ${ }^{8}$.

\section{Experiment I}

\section{Brushing with the Electric Toothbrush}

The mean time estimated for daily brushing is 2 minutes $^{9}$, corresponding to the time of 5 seconds per dental surface 4 . Brushing was done twice a day for 5 seconds on each SP, totaling 1 minute and 10 seconds per week. The Oral B Professional Care SmartSeries 5000 electric toothbrush was placed at an angle of approximately $90^{\circ}$ to the surface of the SPs. It was held in position by a device developed for this purpose.

During brushing, the intensity of the applied force should be controlled and maintained at approximately $1.5 \mathrm{~N}(150 \mathrm{~g})$ to avoid abrasive, superficial wear ${ }^{10}$. The electric toothbrush used has a device to indicate the force, which emits a sound when excessive force is applied. According to the manufacturer's guidelines, the bristles of the toothbrush were initially soaked in distilled water and then the toothpaste was dispensed according to the group to be brushed. A new 
toothbrush was used for each group, corresponding to the Oral- $\mathrm{B}^{\circledR}$ CrossAction refill, which has inclined filaments with soft bristles.

\section{Washing and Cleaning of the Specimens}

After brushing, the SPs were washed with distilled water for 10 minutes in the L-200 (Schuster ${ }^{\circledR}$ Ltda.) ultrasonic washer, to clean and remove any residue of the dentifrice. Then, they were dried for 2 minutes using a 25VR-100 triple syringe (AirZap ${ }^{\circledR}$ ).

\section{Evaluation of the Color}

Color was determined using the Vita Easyshade ${ }^{\circledR}$ spectrophotometer, calibrated according to the manufacturer's recommendations. The spectrophotometer provides readings in the CIELAB color space in three parameters: $\mathrm{L}^{*}$, corresponding to luminosity, ranging from 0 to 100 ; $\mathrm{a}^{*}$, corresponding to the red-green axis, ranging from -80 to +80 ; and, $\mathrm{b}^{*}$, corresponding to the yellow-blue axis, ranging from -80 to +80 . This system also permits measuring the difference in color between two samples and demonstrates the color variation $(\Delta \mathrm{E})$ between two readings. The color readings were obtained in triplicate after the artificial darkening process and after brushing with the electric toothbrush. $\Delta \mathrm{E}$ values less than 3.3 are not considered perceptible to the human eye, so the spectrophotometer is a suitable resource for this evaluation ${ }^{11}$.

\section{Experiment II}

\section{Test of Abrasion}

To perform the test of abrasion, 100,000 cycles of simulated brushing were conducted, corresponding to 2 years of brushing, and used the soft bristle toothbrush heads (Classic Clean/Colgate-Palmolive Company ${ }^{\circledR}$, São Paulo, Brazil). The speed of the simulated brushing machine (ElQuip ${ }^{\circledR}$, São Paulo, SP, Brazil) is 4.5 cycles/sec in back-and-forth movements. For each $\mathrm{SP}$, there was a toothbrush and a $20 \mathrm{~mL}$ syringe that injected $0.4 \mathrm{~mL}$ of the dentifrice solution every 2 minutes. Three time-intervals, from the 6 - $(25,000$ cycles $), 12$ - (50,000 cycles) and 24 - month $(100,000$ cycles) periods, were analyzed.

\section{Preparation of the Dentifrice Solutions}

Each dentifrice was weighed on an analytical Scale (model AY 220, Shimadzu ${ }^{\circledR}$ do Brasil Ltda., São Paulo, SP, Brazil) and diluted in a 1:2 ratio in distilled water ${ }^{12}$. It was subjected to $\mathrm{pH}$ verification in triplicate (pHmetro Model 2000 Quimis ${ }^{\circledR}$ Aparelhos Científicos Ltda., Diadema, São Paulo, Brazil) prior to the simulated brushing.

\section{Washing and Cleaning of the Specimens}

To evaluate color, roughness and mass, the SPs were removed from the brushing machine and placed in the L-200 ultrasonic washer for 10 minutes with distilled water to clean any remaining dentifrice residue. They were dried for 2 minutes using a 25VR-100 triple syringe. 


\section{Evaluation of the Color}

Evaluation of the color was performed according to Experiment I, using the Vita Easyshade ${ }^{\circledR}$ spectrophotometer and the CIELAB color space.

\section{Evaluation of the Roughness}

Evaluation of the superficial roughness of the SPs was conducted using a rugosimeter (Model SJ 301 Mitutoyo $^{\circledR}$, Kawasaki, Japan). Readings were made in four different directions for each specimen, to obtain the mean of the four measurements at the end. The cut-offs used were $0.8 \mathrm{~mm}$ and the " $N$ " (fragmentation number of the reading) in 5, so that the tip of the sensor ran the entire length of the specimen in each direction. The superficial roughness of each specimen was evaluated before and after the simulated brushings at the 6-, 12- and 24-month periods.

\section{Evaluation of the Mass}

The mass (g) of the 80 SPs was obtained in triplicate after polishing, and at the 6-, 12- and 24-month periods of simulated brushing, using an analytical scale.

\section{Statistical Analysis}

Descriptive and exploratory analyses of all variables were conducted. The exploratory analyses indicated that the data were asymmetrically distributed, and generalized linear models were applied to the variables corresponding to the values of the $\Delta \mathrm{E}$, roughness and mass. For the $\Delta \mathrm{E}$ analysis, the group effect in the model was considered. For the other variables, the group effect and the measures repeated in time were considered.

In the experiment with the electric toothbrush, the Kruskal Wallis and Dunn's non-parametric tests were used for between-groups comparisons, and the Wilcoxon test was used for comparisons between the initial and final times. In the experiment with the toothbrushing machine, the Kruskal Wallis and Dunn's tests were used for between-groups comparisons, and the Friedman and Nemenyi tests were used for comparisons among the four times. Data analysis was conducted using the R program, with a $5 \%$ level of significance.

\section{RESULT}

The results are presented according to the experimental stages of the study. In Experiment I, conducted using the electric toothbrush, the color variation of the SPs was evaluated. In Experiment II, conducted using the simulated brushing machine, the parameters of color, roughness and mass of the SPs were evaluated.

\section{Experiment I}

\section{Evaluation of Color}

Greater color variation $(\Delta \mathrm{E})$ was observed in the group GT6 than in the groups CG, GT2, GT4 and GT5 ( $<<0.05)$. Groups GT2, GT4 and GT5 did not differ significantly from CG $(\mathrm{p}>0.05)$ (Figure 1). 


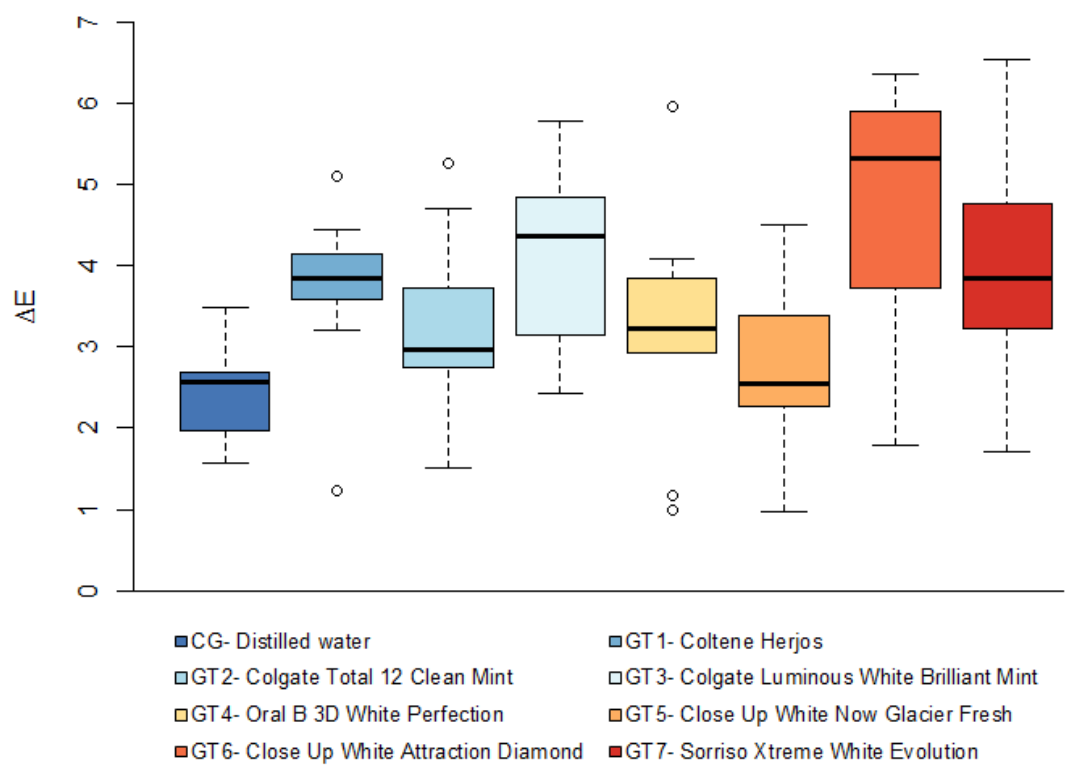

Figure 1. Color variation $(\Delta \mathrm{E})$ by group after one month of brushing with the electric toothbrush.

\section{Experiment II}

\section{Evaluation of Color}

Evaluation of color variation $(\Delta \mathrm{E})$ after 6,12 and 24 months of simulated brushing showed that all groups differed from CG. After 6 months of brushing, the variation was significantly greater in GT6 and GT7 than in CG, GT2 and GT4 $(\mathrm{p}<0.05)$. After 12 months, the color variation was significantly greater in GT7 than in the other groups $(\mathrm{p}<0.05)$, with the exception of group GT6 from which it did not differ significantly ( $p>0.05$ ). After 24 months, groups GT6 and GT7 showed significantly greater $\Delta \mathrm{E}$ than groups CG, GT2, GT3 and GT4 (p<0.05) (Figure 2).

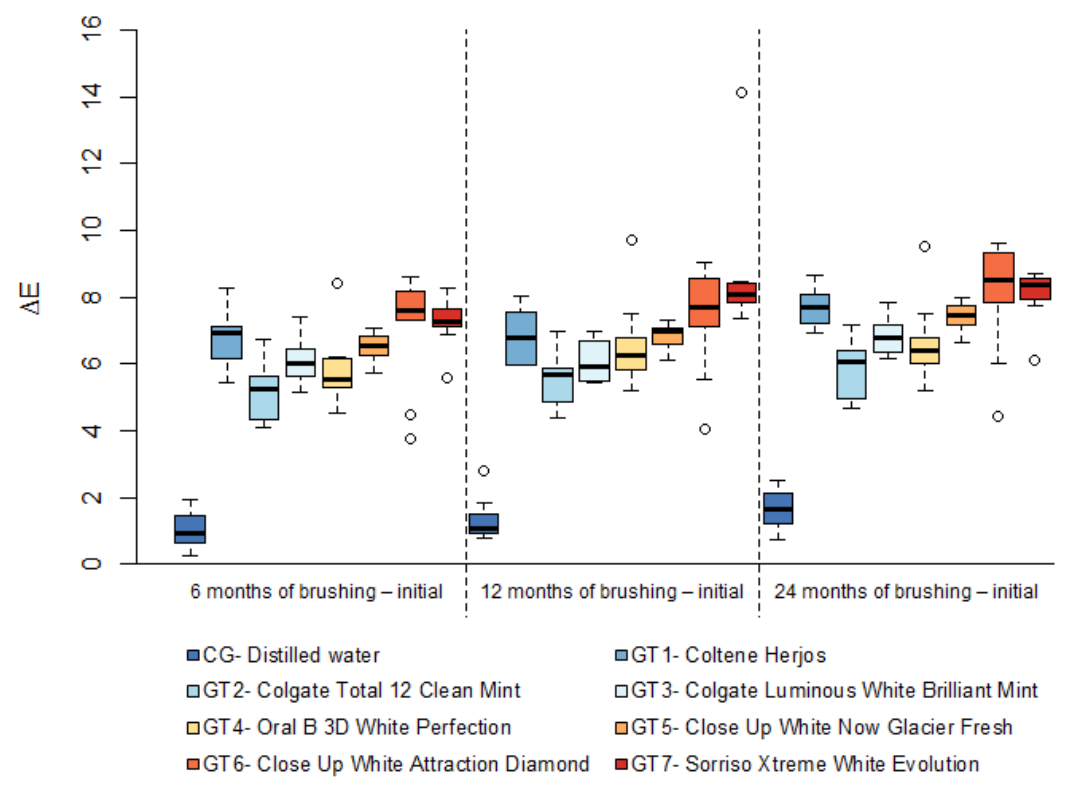

Figure 2. Color variation $(\Delta \mathrm{E})$ by group and by time after simulated brushing with the toothbrushing machine. 


\section{Evaluation of Roughness}

There was a significant decrease in roughness among all groups $(\mathrm{p}<0.05)$. After 24 months of simulated brushing, roughness was significantly less in groups GT2, GT3, GT5, GT6 and GT7 compared to $\mathrm{CG}(\mathrm{p}<0.05)$. When the test groups were compared, roughness was statistically less in groups GT5 and GT7 than in groups GT1, GT4 and GT6 (p<0.05) (Figure 3).

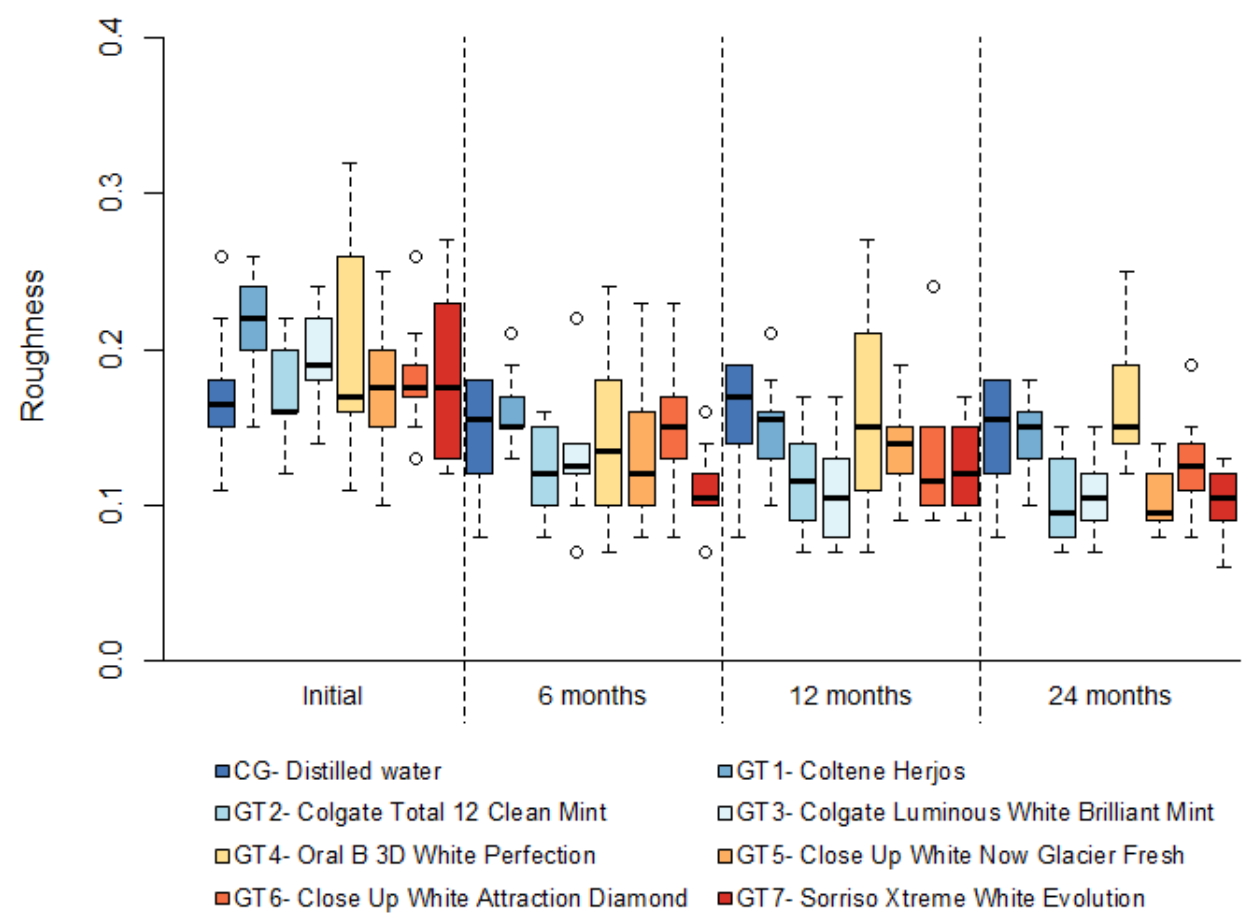

Figure 3. Evaluation of roughness of the SPs by group and by time after simulated brushing.

\section{Evaluation of Mass}

After 24 months of simulated brushing, there was a statistically significant decrease of mass in groups GT1, GT3, GT4, GT5, GT6 and GT7 $(\mathrm{p}<0.05)$. However, despite being statistically significant, the differences were small and may not represent clinical relevance. When all groups were compared, despite the decrease of mass in some, there was no significant difference among them ( $p>0.05)$ after 24 months of brushing.

\section{Evaluation of the $\mathrm{pH}$}

Regarding the $\mathrm{pH}$ values of the evaluated solutions of the dentifrices, it was possible to identify values that ranged from $\mathrm{pH} 6.8$ to $\mathrm{pH} 8.8$.

\section{DISCUSSION}

The present study demonstrated that brushing with an electric toothbrush for one month and simulated brushing for 24 months with whitening dentifrices containing Blue covarine promoted improvement in the color of the nanoparticulate composite resin after artificially darkening with coffee. Brushing with the dentifrices provided whitening of the resin without increasing superficial roughness or loss of mass. 
Among the aesthetic restorative materials available, composite resins are considered the materials of first choice for restorative procedures. These composites present stability of color, compatibility with oral tissues, longevity and good aesthetics. In the present study, the nanoparticulate composite resin Filtek Z350 XT was used due to its physical properties, greater resistance to wear, superficial smoothness, gloss and durability ${ }^{13,14}$. The durability and appearance of composite resin restorations are influenced by the characteristics of the material, time and quality of brushing, and abrasiveness of the dentifrices. The pigmentation of the restorations can occur by adsorption of pigments from exogenous sources such as nicotine, coffee, tea and colorized foods, compromising their appearance ${ }^{15}$.

To maintain oral hygiene, the use of a toothbrush associated with a dentifrice is essential for preventing cavities, gingivitis, also for cleaning and dental polishing ${ }^{2}$. Studies conducted using an electric toothbrush and a manual toothbrush, with different types of bristles, have been performed to verify their abrasive action on dental surfaces. Regardless of the type of toothbrush, those studies agree that toothbrushes with soft bristles are the most suitable for daily brushing 16,17 .

The presence of the abrasive system in the dentifrices is indispensable, so international standards have been established regarding the relative abrasiveness of the dentifrices in order to limit possible alterations to the surface of the enamel and restorative materials. Dentifrices are classified according to the potential for abrasiveness in relation to the dentin, Radioactive Dentin Abrasion (RDA), which expresses the cleaning capacity of dentifrices in different degrees of abrasiveness, classified as high, medium and low. The greater the RDA, the greater the risk of damage to the dental tissues and aesthetic restorations ${ }^{18}$. Evaluation of the labeling of the tested dentifrices showed the absence of this information in the respective packaging.

Studies demonstrate that several factors can alter the abrasiveness of the dentifrice, such as the type of abrasive and its concentration, strength, frequency and duration of brushing, type of toothbrush and the stiffness of the filament of the bristles ${ }^{18,19}$. Regarding the toothbrushes, those with hard bristles promote greater wear on the enamel surface when compared to those with soft and medium bristles ${ }^{18}$. In the present study, an electric toothbrush and manual toothbrushes with soft bristles were used. It was observed through control groups that the bristles of the toothbrushes used do not damage the resin surface.

Dentifrices for daily use, with different therapeutic purposes, are available on the market. Whitening dentifrices have components similar to conventional dentifrices such as detergents, moisturizers, flavorings and abrasives. Mechanical, chemical and optical whitening agents are found, associated or not, in the compositions of these dentifrices. The abrasives, in addition to the capacity to remove extrinsic stains, also have a polishing action on the surface of the teeth2 However, their action is influenced directly by the size, shape, hardness and concentration of their particles ${ }^{20}$. Analysis of the labeling showed that all the dentifrices evaluated contained abrasive silica in their composition. There is, however, variation regarding the presence of other abrasive agents, such as mica and calcium carbonate.

Evaluation of the color variation, after brushing with the electric toothbrush for one month, showed that most of the whitening dentifrices promoted a reduction in the color shades of the SPs, when compared to the control group. The greatest variation occurred in group GT6, that brushed with the dentifrice that contained silica and mica, in addition to Blue covarine. However, the observed effect cannot be considered as proof of the whitening action of Blue covarine, since the groups that brushed with the prophylactic paste (GT1), with the whitening dentifrice containing Blue lake (GT3), and the dentifrice with the association of Blue covarine with Blue lake (GT7), had effects similar to GT6.

An investigation conducted to verify the whitening effect of dentifrices for conventional use and whiteners on the color stability of different composite resins and a glass ionomer cement modified by resin, through brushing with the electric toothbrush for periods of $0,1,7,30$ and 
90 days, showed that the dentifrices did not promote significant color change in the tested resins, even that which contained the optical agent Blue covarine ${ }^{6}$. These results are in accordance with the present study in which, after brushing with the electric toothbrush and dentifrices containing Blue covarine for a period equivalent to one month, no significant color variation was observed in the groups that brushed with conventional dentifrice (GT2) and dentifrices containing Blue covarine (GT4 and GT5), when compared to the control group.

The prophylactic paste for professional use, in addition to silica in its composition, also contained calcium carbonate. This is an abrasive with regularly shaped particles and with less abrasive potential in relation to silica 20,21 . When compared to the other groups, the group that brushed with prophylactic paste (GT1) presented results similar to groups GT3 and GT7, differing from groups CG and GT5. This result shows that, despite being a product restricted to professional use, the prophylactic paste presented a behavior similar to that of the whitening dentifrices for daily use.

The optical whitening agent, Blue covarine, is present in whitening dentifrices associated with mechanical agents. Hydrated silica is the most used abrasive in these dentifrices². Studies carried out to verify the effect of whitening dentifrices containing Blue covarine, conducted using simulated brushing on bovine teeth in order to evaluate color, showed that after brushing there was an increase in the whitening of the dental surface ${ }^{12,22}$. On the other hand, studies conducted on composite resin using simulated brushing and the electric toothbrush, did not demonstrate change of color in the composite resin ${ }^{5,6}$.

In the present study, color evaluation after simulated brushing at 6, 12 and 24 months demonstrated that the groups which presented the greatest averages of color variation were those brushed with whitening dentifrices that showed the association of silica with Blue covarine in their composition. Groups GT6 and GT7, in addition to this association, showed the mechanical agent mica and the bright blue pigment/Blue lake, respectively, in their composition. The observed results seem to be related to the association of mechanical and optical agents and their concentrations. However, information related to the concentration of the components of the dentifrices is not provided in the packaging.

An in vitro study to evaluate dental whitening through the use of dentifrices with different blue pigments, observed that Blue covarine, among the substances tested, provided the most whitening of the dental surface ${ }^{1}$. The present study demonstrated that the groups that brushed with a dentifrice containing Blue covarine presented better results when compared to the group that brushed with a dentifrice containing the pigment Blue lake. Whitening dentifrices containing Blue covarine are credited with effective action in promoting dental and restorative materials whitening, through the immediate deposition of a semitransparent film with a bluish tint on the surface, when compared to dentifrices for conventional use $\mathrm{s}^{2,3,5}$.

A comparative study, conducted to verify the abrasiveness of conventional and whitening dentifrices with two composite resins, concluded that the greater the brushing time, the greater the color alteration of the nanoparticulate composite resin without, however, any alteration in the surface roughness ${ }^{23}$. This result is in accordance with the findings of the present study, despite methodological differences.

Regarding the variation in roughness, analyzing the time variable, it was observed that after 6,12 and 24 months of simulated brushing there was no significant difference in roughness with the polishing of the surfaces of the resin SPs. After 24 months of brushing, the roughness was less in groups GT5 and GT7, compared with the other groups. However, it did not differ from group GT2 that brushed with the conventional use dentifrice. Analysis of the composition of these dentifrices showed the presence of silica in all of them, although qualitative similarities and differences were observed regarding other mechanical agents present in their compositions. The concentrations of the components of the dentifrices are not described in their packaging, due to 
patent confidentiality of the manufacturing companies ${ }^{22}$. This makes it difficult to interpret the data and compare the studies.

An in vitro study was conducted to verify the effect of two whitening, and one conventional, dentifrices. The roughness of the composite resin Z350 XT was evaluated after simulated brushing for a period of 15 days with 2 daily brushings of 2 minutes each, using toothbrushes with soft bristles. The evaluation of roughness was conducted using a rugosimeter, and demonstrated that there was a significant increase in roughness in all groups regardless of the dentifrice used ${ }^{14}$. This finding differs from the present study since the polishing of the surfaces, and not the wear on them, was observed.

Evaluation of the superficial roughness of two composite resins, subjected to simulated brushing using a brushing machine for 6,12 and 24 months, treated with three dentifrices, for conventional use, whitening and desensitizing, with brushing force equivalent to $200 \mathrm{~g}$ using toothbrushes with soft bristles, showed that the greater the brushing time, the greater the superficial roughness of the composite resins ${ }^{13}$. These results differ from the present study, which found no increase in roughness during the 6,12 and 24 month periods evaluated, with polishing of the surface of the nanoparticulate composite resin without damage to its structure.

An in situ study, conducted to evaluate the variation in the mass of acrylic resin, found that brushing for two years using dentifrices containing Blue covarine provided greater loss of mass in relation to conventional and whitening dentifrices without Blue covarine $e^{24}$. The loss of mass of the specimens can be used as a reference to determine structural losses in restorative materials. In the present study, it was demonstrated that there was no significant loss of mass of the composite resin evaluated during the periods of simulated brushing.

The influence of simulated brushing with a conventional dentifrice on the superficial roughness of four types of composite resins using a force of $0.2 \mathrm{~N}$, after 5,000, 10,000 and 20,000 cycles, showed that the Filtek Z350 XT resin presented significantly less roughness in relation to the other resins evaluated and that there was no difference in mass among the samples studied ${ }^{25}$. These results are in accordance with the present study, in which no increase in roughness or loss of mass was verified, demonstrating that there was no wearing of the restorative material in the periods evaluated.

In addition to the factors involved in dental brushing that can interfere with the superficial roughness of the enamel and of the restorative materials, the $\mathrm{pH}$ of the solutions of the dentifrices also exerts an influence. This is because dentifrices with $\mathrm{pH}$ below what is critical for demineralization of the dental structure can contribute to greater abrasion due to a possible association of the erosive and abrasive effects ${ }^{9,20}$. In the present study, all the solutions of dentifrices studied presented $\mathrm{pH}$ greater than or equal to 6.8 , therefore not interfering in the abrasiveness of the dentifrices.

Despite the growing number of studies using different dental materials and tissues to test the effect of whitening dentifrices, there are still few studies that evaluate the action of whitening dentifrices containing Blue covarine in composite resins. The results found in the present study demonstrate the role of these dentifrices in promoting the whitening of composite resin without structural alterations. However, it should be taken into account that the action of this optical agent in isolation was not evaluated in this study.

\section{CONCLUSION}

Dentifrices containing the optical agent Blue covarine did not cause alteration of the roughness or loss of mass of the nanoparticulate composite resin. However, the whitening effect achieved seems to be more related to the action of this agent combined with the abrasives present in the formulations of the whitening dentifrices than to its isolated action. 


\section{ACKNOWLEDGEMENTS}

The Higher Education Personnel Coordination Institution - CAPES, Oral Biochemistry Laboratory of the Federal University of Bahia and Rafael Bovi Ambrosano for the help and availability.

\section{REFERENCES}

1. Joiner A, Philpotts CJ, Alonso C, Ashcroft AT, Sygrove NJ. A novel optical approach to achieving tooth whitening. J Dent. 2008;36(Suppl 1):S8-14. http://dx.doi.org/10.1016/j.jdent.2008.02.005. PMid:18646364.

2. Joiner A. Whitening toothpastes: a review of the literature. J Dent. 2010;38(Suppl 2):e17-24. http://dx.doi.org/10.1016/j.jdent.2010.05.017. PMid:20562012.

3. Joiner A, Luo W. Tooth colour and whiteness: a review. J Dent. 2017 Dec;67S:S3-10. http://dx.doi.org/10.1016/j.jdent.2017.09.006. PMid:28928097.

4. Pertiwi UI, Eriwati YK, Irawan B. Surface changes of enamel after brushing with charcoal toothpaste. J Phys Conf Ser. 2017 Aug;884(1):012002. http://dx.doi.org/10.1088/1742-6596/884/1/012002.

5. Ashcroft AT, Cox TF, Joiner A, Laucello M, Philpotts CJ, Spradbery PS, et al. Evaluation of a new silica whitening toothpaste containing blue covarine on the colour of anterior restoration materials in vitro. J Dent. 2008;36(Suppl 1):S26-31. http://dx.doi.org/10.1016/j.jdent.2008.02.007. PMid:18646367.

6. Hashemikamangar SS, Hoseinpour F, Kiomarsi N, Dehaki MG, Kharazifard MJ. Effect of an optical whitening toothpaste on color stability of tooth-colored restorative materials. Eur J Dent. 2020 Feb;14(1):85-91. http://dx.doi.org/10.1055/s-0040-1705071. PMid:32168535.

7. Silveira RR, Silva MES, Souza EL, Giovannini JFBG, Francisconi PAS. Avaliação da resistência de união de reparos de resina composta, utilizando-se diferentes tratamentos de superfície. Arq Odontol. 2012 Out-Dez;48(4):234-41.

8. Reinhardt JW, Balbierz MM, Schultz CM, Simetich B, Beatty MW. Effect of tooth-whitening procedures on stained composite resins. Oper Dent. 2019 Jan-Feb;44(1):65-75. http://dx.doi.org/10.2341/17301-L. PMid:29570025.

9. Jiang N, Zhang C, Agingu C, Attin T, Cheng H, Yu H. Comparison of whitening dentifrices on the effectiveness of in-office tooth bleaching: a double-blind randomized controlled clinical trial. Oper Dent. 2019 Mar-Apr;44(2):138-45. http://dx.doi.org/10.2341/17-333-C. PMid:30106335.

10. Esteves-Oliveira M, Santos NM, Meyer-Lueckel H, Wierichs RJ, Rodrigues JA. Caries-preventive effect of anti-erosive and nano-hidroxyapatite-conteining toothpastes in vitro. Clin Oral Investig. 2017 Jan;21(1):291-300. http://dx.doi.org/10.1007/s00784-016-1789-0. PMid:26993660.

11. Nasim I, Neelakantan P, Sujeer R, Subbarao CV. Color stability of microfilled, microhybrid and nanocomposite resins-an in vitro study. J Dent. 2010;38(Suppl 2):e137-42. http://dx.doi.org/10.1016/j.jdent.2010.05.020. PMid:20553993.

12. Tao D, Sun JN, Wang X, Zhang Q, Naeeni MA, Philpotts CJ, et al. In vitro and clinical evaluation of optical tooth whitening toothpastes. J Dent. 2017 Dec;67S:S25-8. http://dx.doi.org/10.1016/j.jdent.2017.08.014. PMid:28859964.

13. Monteiro B, Spohr AM. Surface roughness of composite resins after simulated toothbrushing with different dentifrices. J Int Oral Health. 2015 Jul;7(7):1-5. PMid:26229362.

14. Santos JHA, Silva NML, Gomes MGN, Paschoal MAB, Gomes IA. Whitening toothpastes effect on nanoparticle resin composite roughness after a brushing challenge: an in vitro study. J Clin Exp Dent. 2019 Apr;11(4):e334-9. http://dx.doi.org/10.4317/jced.55533. PMid:31110612. 
15. Mozzaquatro LR, Rodrigues CS, Kaizer MR, Lago M, Mallmann A, Jacques LB. The effect of brushing and aging on the staining and smoothness of resin composites. J Esthet Restor Dent. 2017 Apr;29(2):E4455. http://dx.doi.org/10.1111/jerd.12293. PMid:28194869.

16. Rosema N, Slot DE, van Palenstein Helderman WH, Wiggelinkhuizen L, Van der Weijden GA. The efficacy of powered toothbrushes following a brushing exercise: a systematic review. Int J Dent Hyg. 2016 Feb;14(1):29-41. http://dx.doi.org/10.1111/idh.12115. PMid:25545231.

17. Furlan GHV, Braga SRM, Steagall-Júnior W, Sobral MAP. Desgaste dental causado por diferentes cerdas de escovas dentais. Rev Inst Ciênc Saúde. 2005 Out-Dez;23(4):305-8.

18. Lippert F, Arrageg MA, Eckert GJ, Hara AT. Interaction between toothpaste abrasitivity and toothbrush filament stiffness on the development of erosive/abrasive lesions in vitro. Int Dent J. 2017 Dec;67(6):344-50. http://dx.doi.org/10.1111/idj.12305. PMid:28574173.

19. Bizhang M, Riemer K, Arnold WH, Domin J, Zimmer S. Influence of bristle stiffness of manual toothbrushes on eroded and sound human dentin - an in vitro study. PLoS One. 2016 Apr;11(4):e0153250. http://dx.doi.org/10.1371/journal.pone.0153250. PMid:27070901.

20. Andrade A Jr, Machado WAS. Caracterização físico-química dos componentes inorgânicos dos dentifrícios. Rev ABOPREV. 2000;3(2):50-6.

21. Hara AT, Turssi CP. Baking soda as an abrasive in toothpastes: mechanism of action and safety and effectiveness considerations. J Am Dent Assoc. 2017 Nov;148(11S):S27-33. http://dx.doi.org/10.1016/j.adaj.2017.09.007. PMid:29056187.

22. Odilon NN, Lima MJP, Ribeiro PL, Araújo RCP, Campos EJ. Avaliação in vitro do efeito de dentifrícios branqueadores contendo Blue Covarine sobre o esmalte dentário bovino. Rev Odontol UNESP. 2018 Dec;47(6):388-94. http://dx.doi.org/10.1590/1807-2577.12118.

23. Roselino LMR, Chinelatti MA, Alandia-Román C, Pires-de-souza FCP. Effect of brushing time and dentifrice abrasiveness on color change and surfasse roughness of resin composites. Braz Dent J. 2015;26(5):507-13. http://dx.doi.org/10.1590/0103-6440201300399. PMid:26647937.

24. Roselino LMR, Tirapelli C, Pires-de-Souza FCP. Randomized clinical study of alterations in the color and surfasse roughness of dental enamel brushed with whitening toothpaste. J Esthet Restor Dent. 2018 Sep;30(5):383-9. http://dx.doi.org/10.1111/jerd.12379. PMid:29603865.

25. Al Khuraif AAA. An in vitro evaluation of wear and surface roughness of particulate filler composite resin after tooth brushing. Acta Odontol Scand. 2014 Nov;72(8):977-83. http://dx.doi.org/10.3109/00016357.2014.933251. PMid:25220522.

\section{CONFLICTS OF INTERESTS}

The authors declare no conflicts of interest.

\section{${ }^{*}$ CORRESPONDING AUTHOR}

Rafaela Silva Oliveira, UFBA - Universidade Federal da Bahia, Instituto de Ciências da Saúde, Av. Reitor Miguel Calmon, sala 413, 4ํaㄱar, s/n, Vale do Canela, 40110-100 Salvador - BA, Brasil, e-mail: rafa92oliver@gmail.com

Received: October 23, 2020

Accepted: December 15, 2020 